\title{
Use of Recycled Glass Bottles as Fine Aggregates in Concrete Mixture
}

\author{
Tomas U. Ganiron Jr \\ College of Architecture, Qassim University, Buraidah City \\ Graduate School, Adamson University, Manila \\ tomasuganironjr@gmail.com
}

\begin{abstract}
This experimental study aimed to design a concrete mixture with recycled bottles as an alternative fine aggregates for mass housing projects that will meet the American Society for Testing and Materials (ASTM) requirements in order to help contribute to the industry in saving the environment, to encourage the government to find solutions regarding the disposal to landfills of waste materials and provide new knowledge to the contractors and developers on how to improve the construction industry methods and services by using recycled bottles, and to sustain good product performance and meet recycling goals. A conventional concrete product was compared to concrete with recycled bottles of the same proportions. Observations from the tests performed were conducted in the laboratory where precise data were gathered and completely attained.
\end{abstract}

Keywords: Concrete, fine aggregate, recycled bottles, sustainable, waste materials

\section{Introduction}

As time goes by, human civilization is continuously becoming more industrialized. More factories are built, vehicles are continuously growing in number, and buildings were built all around. As a result of these, our natural environment was permanently changed from what it has been twenty years or more.

Over, the last several decades, sociologists have investigated the public's increasing concern about the environment, but they have had little success explaining attitudes. toward the environment or the adoption of pro-environment behaviors like recycling The researcher examine the role of social context in the link between individual attitudes about the environment and recycling behavior by comparing communities that vary in their access to recycling programs. Results show that people with access to a structured recycling program have much higher levels of recycling than do people lacking such access. Furthermore, individual attitudes toward the environment affect recycling behavior only in the community with easy access to a structured recycling program. Individual concern about the environment enhances the effect of the recycling program, but does not overcome the barriers presented by lack of access.

The human population is continuously growing in number, because of this; there is a great demand of constructing more structures to facilitate the needs of the community. Quarry operations become rampant to satisfy the need for gravel and sand for construction. As a consequence there are massive destruction of mountains which has been one of the major costs of landslides, and flashfloods during earthquakes and typhoons resulting to loss of thousands or even millions of lives. 
The results of this study are expected to benefit the following: (1) the students of other fields could be provided with a reference and can give them knowledge about recycled glass bottles as an alternative fine aggregate for concrete mix. This study will encourage them to study other materials that can be used as a construction material and awaken their minds regarding environmental protection; (2) the contractors and home builders will be provided with knowledge and information to improve the method of construction using other materials as fine aggregate to concrete cement for construction; (3) the government and non-government sectors are given new ideas of maximizing their resources on construction projects. This study will also make them knowledgeable that junk materials can be used as construction material and urge them to finance further studies for the development of this study.

A number of attempts have been made to successfully use glass as an additive in concrete compositions. Certain compositions proposed have been successfulin accomplishing specific goals.

\section{Literature Review}

As a tropical country, Philippines is one of the world's largest producers of coconut products such as coconut oil, copra (dried coconut) and desiccated coconut. Historically, Southern Tagalog, Bicol regions of Luzon and Eastern Visayas were the centers of coconut productions of land with coconut trees and its population was at least partly dependent on it for their livelihood yet, large amount of agricultural waste was disposed. Poor management of disposing may lead to social and economic problem.

Recycling of the disposed material is one method of treating the agricultural waste. The used of coconut fiber and coconut shell could be a valuable substitute in the formation of composite material that can be used as a housing construction, such as concrete hollow block [1].

Coconut is famous as multi-function plant that all parts of its plant can be used for various activities $[1,2]$. The use of this agricultural waste due to an assumption is that it can replace the existing material used in commercial product in order to reduce cost or improve mechanical properties of the composite material. Industrialists in most of the coconut producing countries hail the economic, environmental and technological benefits of utilizing coconut farm wastes [2]. On the farmers' side, agricultural residues can be a source of extra income. Traditionally, coconut farmers dispose the husks, spate, petiole and leaves by burning or allowing these farm wastes to rot in the field [1, 2]. However, worldwide interest in using farm residues for value-added products means that farmers can generate additional income aside from amassing environmental dividends. Studies have shown that burning of agricultural wastes causes air pollution, soil erosion and even a decrease in soil biological activity that can eventually lead to decreased soil fertility [3]. On the other hand, allowing farm residues to rot in the field may improve the productivity of the soil but the process of decomposition is very slow leading to accumulation of piles of agricultural wastes that can cause phytosanitary problem to the coconut plantation, since decaying debris is ideal breeding place for coconut pest like the rhinoceros beetle $[2,3]$.

Using agricultural and forest residues for industrial purposes is a much more environment-safe and friendly more than any other method of wastes disposal being commonly adopted nowadays. Research and development in the construction industry are shifting towards exploration of cellulose farm wastes and forest residues processing and production for building materials [3]. The tremendous potential of agricultural and forest residues can be a solution to the problem of inadequate supply and high cost of 
conventional timbers and dependence from imported building materials. Current research and development efforts in the field of building materials should be supportive of policies of most governments that are aimed in the promotion of import substitution schemes, employment generation and self-reliance [3]. The enormous amount of residues that shall be generated from the farm and forest plantation would then make a stable source of alternative materials for the purpose of building affordable housing units for the majority of the country's population.

Considered the most useful tree in the world, the coconut palm provides food, drink, clothing, shelter, heirloom history, and financial security [3]. Hardly an inch of the coconut palm goes to waste in countries such as the Philippines where families rely on the coconut palm for survival and refer to it as the "tree of life."

The shell, husk, roots of the tree, fronds, flowers, and wood of the trunk are also become useful products. Charcoal filters used in gas masks and cigarettes are made from coconut shells that are burned, leaving pure carbon behind. Charcoal has the ability to trap microscopic particles and impurities and prevent absorption [4]. Charcoal made from coconut shells produces filters of exceptional high performance.

One third of the coconut's make-up is the hairy husk that is soaked in salt water until it is soft enough to spin into rope or twine that is known for its durability [5]. The rope, called coir but pronounced coil, is highly resistant to salt water and does not break down like other fibers including hemp [6]. The coconut husk has household practicality in tropical countries where coconuts are part of almost every cuisine. The husk provides fuel for cooking as well as fiber for making clothing.

Building materials from agricultural and forest wastes are ideal for socialized or low cost housing since these are generally cheaper than conventional materials [7]. For example, residues from coconut plantation like husks, fronds and spate can be processed and transformed into excellent stabilized cement-bonded boards or wall panels and corrugated roofing sheets at a much reduced production cost than the conventional cement blocks, galvanized iron sheets, asbestos panels or plywood sheets. Likewise, rice hull/straw, corn stalks, abaca wastes and sugar cane bagasse are locally available materials that can be readily used in manufacturing cement-bonded boards. In addition, indigenous and small diameter trees like "bagalunga" and giant "ipil-ipil" are abundant in coconut plantations particularly in Mindanao, Philippines, either as intercropped or naturally-grown, which can be economically processed into cementbonded boards [7]. The availability of suitable materials is intimately linked to the development of a new product, such as producing a concrete hollow block using coconut fibers and shells. Generating this product using agricultural waste will introduce alternative construction materials with a low production cost and lessen the social and environmental problems [7, 8]. Modern construction technologies being developed, respond to ecological and social issues of excessive use of raw materials from nature.

\section{Experimental Investigation}

This experimental research focuses on the effect of using recycled bottles as concrete material for mass housing projects. This research aims to determine the effect of using recycled bottles on the properties of hardened concrete namely: compressive strength and modulus of elasticity. Also included, are the effect of recycled bottles on watercement ratio, quality and size of aggregates and consistency of the mix. Experiments shall be conducted to acquire the necessary data needed in the analysis. Each 
experiment shall be conducted in accordance with the standards which are applicable in our country, in which in our case, specified by ASTM requirements.

Bottles from junkshops are used in this study. These bottles are crushed and use as a replacement for fine aggregates for concrete mixture. The researcher used manually crushed and clean bottles and chosen bottles with the same property for uniformity. The crushed samples were passed through sieve analysis to ensure that the size of the cullet will be less than $2.0 \mathrm{~mm}$ but greater than $0.0625 \mathrm{~mm}$ with accordance to ASTM standards.

The research concentrates on the effect of using recycled bottles as fine aggregate and not on its properties as an aggregate. The researchers used only Portland Pozzolanic Cement (Type IP), which are commonly used in the field at present, for the specimens. This type of cement has low hardening characteristics [6,7]. It will also cover the difference between the common concrete cement and concrete recycled glass bottles in terms of its properties as a fine aggregate. The specimens are tested for compressive strength using Universal Testing Machine (UTM) on its 7th, 14th, 21st and 28th day of curing. This will be the basis for the data.

The study focuses on compressive strength and elastic modulus. This study also gives emphasis on the environmental concerns and not on its economic aspect. In addition, study is also delimited to durability, creep, shrinkage and water tightness. These four properties of hardened concrete are time-dependent properties which will entail so much time to determine $[8,10,14]$.

\subsection{Project Design}

The researcher believes that glass bottles can be processed into construction grade cullet using any convenient mechanical method. For cullet-aggregate blends, glass cullet can be blended with natural aggregates by any convenient mechanical method. Normal precautions should be followed to prevent segregation.

Typical aggregates for construction include sands, gravels, crushed rock and recycled concrete. The glass cullet and cullet aggregate blends should be compared with these standard specifications for each specific application. The intent of this research is to encourage regulatory departments to amend specifications to allow glass cullet and cullet aggregate blends as an alternative to conventional aggregate in numerous applications. Several states in United States of America, including the Washington State Department of Transportation, have already included specifications for glass aggregate $[9,11,13]$.

The researcher investigates the effects of using recycled glass bottles as an alternative fine aggregate. As shown in figure 1, the researchers used recycled bottles from junkshops. These bottles were cleaned to prevent foreign materials or chemicals from contaminating the specimens. After cleaning, they were crushed manually and sieved to ensure uniformity in particle size. The researcher used Class A mix which has 1:2:4 proportion of cement, sand and gravel respectively. Some percentage of sand was replaced by crushed recycled bottles $(25 \%, 50 \%, 75 \%$, and 100\%) and control mixture was also made available. Three (3) specimens were collected from each mixture using 6"x12" cylindrical molds and these specimens were tested for compressive strength using UTM upon its 7 th, 14 th, 21 st, and 28 th day of its curing. Then, the results were evaluated. 

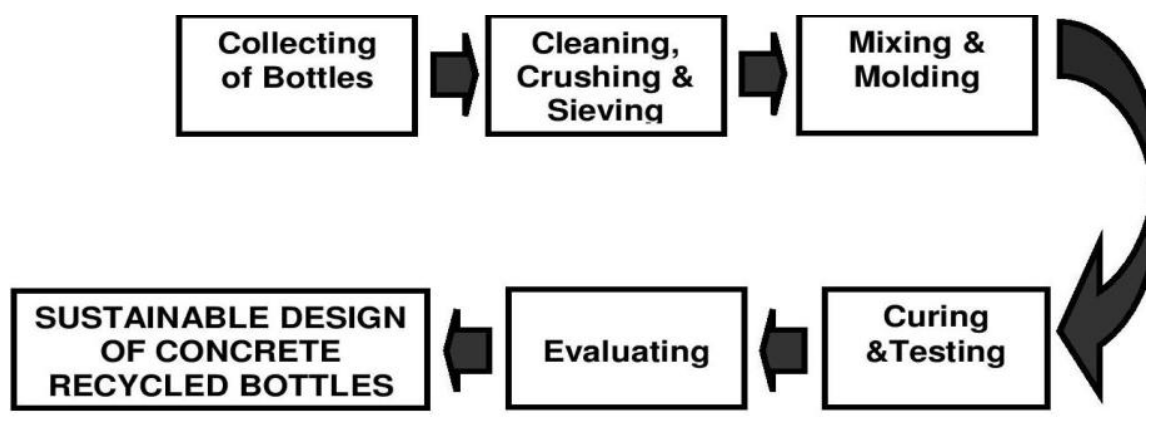

Figure 1. Project Design

\subsection{Sample Identification}

The identification for the specimens is started by a letter which starts from " $A$ " to " $D$ " to designate the curing age of the specimens. The specimens noted with " $A$ " were those tested at its 7th day of curing period. Moreover, those specimens tested on its 14th, 21st and 28th day of curing period were designated with "B", "C" and "D" respectively. Specimens noted with " $D$ " were the most critical because these were tested on its 28th day of curing period and it will be the basis for the final compressive strength (fc') and modulus of elasticity (E). After the letter, it is followed by a numerical value which ranges from " 25 " to " 100 " with an increment of twenty-five (25), which represents the percentage of crushed bottle present in each specimen. The specimens were noted with " 25 ", "50", " 75 " and " 100 " based on the percentage of crushed bottle as against to sand. The last number represents the sample number represents the sample number.

Since three (3) samples are prepared for each mixture for every curing period, it is necessary to have sample number to avoid confusions. Specimens with no crushed bottle aggregate serve as the control specimens. Thus, these samples were labeled as "Control". From the above discussion, figure 2 can be identified as "sample 1 of 7 th day curing age with $100 \%$ crushed bottle as fine aggregate".

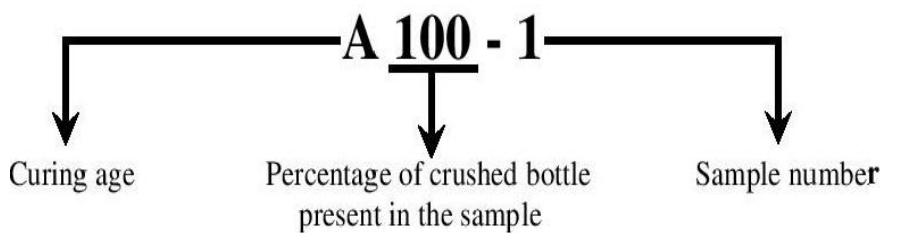

Figure 2. Sample Identification

\subsection{Project Development}

In this project, glass is produced in many forms, including packaging of container glass (bottles, jars), flat glass (windows, windscreens), bulb glass (light globes), cathode ray tube glass (TV screens, monitors, etc.), all of which have a limited life in the form they are produced and need to be reused/recycled in order to avoid environmental problems that would be created if they were to be stockpiled or sent to landfill. Most of the glass produced is in the form of containers, and the bulk of what is collected post-consumer is again used for making containers. The efficiency of this process depends on the method of collecting and sorting glass of different colors [12, 14]. If different color glass (clear, green, a mber) could be separated, then they could be used for manufacturing similar color glass containers. However, when the glass colors 
get mixed, they become unsuitable for use as containers, and are then used for other purposes, or sent to landfill [15-17]. As shown in figure 3, materials needed in the study were collected. The glass bottles were cleaned to make sure that it is free from contaminants and then, it were crushed manually and sieved. The crushed bottles are then added to concrete mixture in replace of some percentage of sand. Upon the 7 th, 14 th, 21 st, and 28th day of its curing, the samples were tested using universal testing machine.

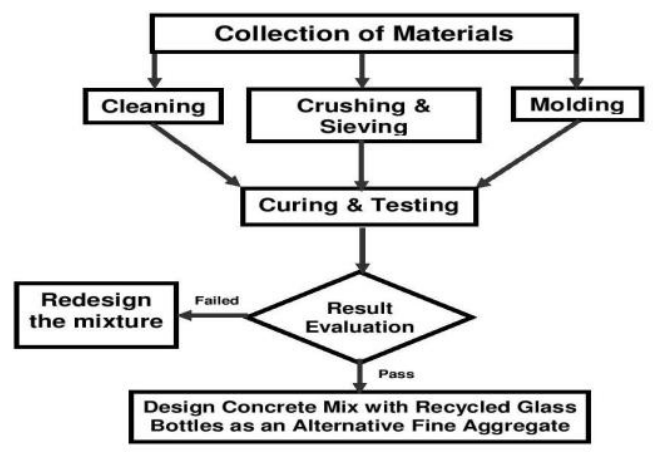

Figure 3. Project Development

\section{Results and Discussion}

\subsection{Water Cement Ratio}

Table 1 represents the water-cement ratio. In terms of water cement ratio, as far as the researchers are concerned, the use of recycled bottles as concrete material has no significant effect. Throughout the mixing and molding stage of the specimens, the researchers used water cement ratio which ranges from 0.55 to 0.65 in terms of mass, and in terms of volume, the ratio is 1.0 approximately. It was observed in this study that as the amount of crushed bottle aggregate increases, the amount of water decreases. To measure the workability, all mixtures were tested for slump. The researches ensure that the value of the slump for all design mix between $1 / 2$ inch and 9 inches to ensure proper workability without sacrificing the strength.

\section{Table 1. Water Cement-ratio}

\begin{tabular}{|c|c|c|c|}
\hline Sample & $\begin{array}{c}\text { Water } \\
(\mathrm{kg})\end{array}$ & $\begin{array}{c}\text { Cement } \\
(\mathrm{kg})\end{array}$ & $\begin{array}{c}\text { Water-Cement } \\
\text { Ratio }\end{array}$ \\
\hline Control & 4.36 & 6.70 & 0.65 \\
\hline $25 \%$ & 4.22 & 6.70 & 0.63 \\
\hline $50 \%$ & 4.00 & 6.70 & 0.60 \\
\hline $75 \%$ & 3.82 & 6.70 & 0.57 \\
\hline $100 \%$ & 3.70 & 6.70 & 0.55 \\
\hline
\end{tabular}

4.1.1. Quality and Size of Aggregates: The researcher also believes that the use of recycled bottles as concrete material has no significant effect on the quality and size of the coarse aggregates. The researchers used materials which readily available at hardware stores. The researchers used $3 / 4$ inch size of coarse aggregate. This size is 
much appropriate to use rather than the larger 1 inch (G1) size because it will fill into the voids much better. The researcher also believe that the use of recycled bottles as concrete material has no significant effect into the quality and size of the coarse aggregates.

4.1.2. Slump Test Results: Table 2 shows the results for slump test. The amount of water greatly affects the consistency of the mixture. Based on the water cement ratio and slump test, the use of recycled bottles as concrete material has no significant effect on the consistency of the mixture. The consistency and procedural of mixing cement and aggregates implementing the Class A mixture.

Table 2. Slump Test Results

\begin{tabular}{|c|c|}
\hline Sample & Slump (inch) \\
\hline Control & 4.00 \\
\hline $25 \%$ & 4.00 \\
\hline $50 \%$ & 5.00 \\
\hline $75 \%$ & 5.00 \\
\hline $100 \%$ & 3.00 \\
\hline
\end{tabular}

\subsection{Comparison between Conventional Concrete and Concrete Recycled Bottles}

4.2.1. Compressive Strength: Depending on the mix and water cement ratio and the time quality of curing, compressive strength of concrete can be obtained up to $97 \mathrm{MPa}$ or more. Conventional concrete production with ordinary aggregates is usually in the 21 $\mathrm{MPa}$ to $83 \mathrm{MPa}$ range with the most common ranges for cast in place buildings from 21 to $41 \mathrm{MPa}[12,16]$. The primary basis on the measure of the strength of concrete is its compressive strength at its 28 th day of curing. The minimum strength requirement for Class A mix of concrete is $20.7 \mathrm{MPa}$ or 3,000 psi. The researchers utilized Portland Pozzolanic Cement (Type 1P) which has low hardening characteristics because this type of cement is commonly used in common types of construction project such as houses at present and it is readily available in the market. Compared to pure Portland Cement or Type 1, Type 1P obtains its maximum compressive strength slower. According to the performed experiments, the average compressive strength of conventional concrete (Control) obtained from the 28th day of curing reached $25.54 \mathrm{MPa}$, while the compressive strength of the samples having crushed bottle to sand ratio of $25 \%, 50 \%$, $75 \%, 100 \%$ are $10.96 \mathrm{MPa}, 11.6 \mathrm{MPa}, 12.08 \mathrm{MPa}$ and $10.12 \mathrm{MPa}$ respectively. These results entail that the required strength was obtained by Concrete Recycled Bottles having different proportions.

4.2.2. Modulus of Elasticity: Unlike steel and other materials, concrete has no definite modulus of elasticity. Its value is dependent on the characteristics of cement and aggregates used, age of concrete and strengths. Due to the non- uniformity of fine aggregates and curing period, the specimens had considerable differences regarding to the modulus of elasticity. According to the performed experiments, the average modulus of elasticity of conventional concrete (Control) obtained from the 28th day of curing reached $28261.35 \mathrm{MPa}$, while the modulus of elasticity of the samples having crushed bottle to sand ratio of $25 \%, 50 \%, 75 \%, 100 \%$ are $18407.76 \mathrm{MPa}, 19792.52$ $\mathrm{MPa}, 19733.29 \mathrm{MPa}$ and $17054.57 \mathrm{MPa}$ respectively. Results show that there is a great 
difference of the modulus of elasticity of the Control specimen among the other samples.

\subsection{Advantages of using Recycled Glass as Concrete Material}

The problem of disposing and managing solid waste materials in other industrial countries has become one of the major environmental, economic, and social issues. Recycling is the most promising waste management process for the disposal of materials in the waste stream. Many virgin and waste materials are widely used in concrete composites as substitute materials for construction. One major advantage of Concrete Recycled Bottle is environment friendly causing of less garbage that will be thrown in the dump site area. Although the impact of this procedure may not be that noticeable at present, the researchers believe that in the near future this will be help not only for the environment but also in the construction industry. Concrete lighter in weight than ordinary sand-and-gravel concrete is used principally to reduce dead load, or for thermal insulation, or fill. Another interesting advantage of Concrete Recycled Bottles is that it is lighter than the conventional concrete mixture. Aside from the advantages as mentioned before, lightweight concrete is more advantageous in reducing the weight of the structure, thus giving smaller base shear for earthquake design purposes. Due to the scarcity of the resources for construction added with the present economic status in our country, the material cost for construction continuous to go up. The Concrete Recycled Bottles has a solution on this problem. The use of the indigenous material for construction produces low cost structures, thus lowering the construction price and gives more profit for the contractor.

\section{Design of Concrete Mixture with Recycled Glass Bottles}

\subsection{Objectives}

1) To help reduce the amount of solid waste materials being damped at landfills.

2) To find other source of aggregate aside from the conventional gravel and sand.

3) To save the material cost for construction by using indigenous materials .

\subsection{Materials}

These are waste glass bottles, Portland cement, sand, gravel, water, crushing tools, mixing tools, cylindrical molds and, experimental and testing equipment.

\subsection{Operation and Testing Procedures}

1) Collect waste glass bottles

2) Clean the collected bottles.

3) Crush the bottles. After crushing, the crushed bottles must pass through sieve number 10 with $2 \mathrm{~mm}$ opening diameter. Make sure that the sizes of particles are uniform.

4) Mix the design mixture desired to be performed. Mix the components thoroughly to ensure that the distribution is even all throughout. Carefully measure the water to be added.

5) Follow the experimental procedures from the ASTM specifications:

a) Making and Curing of Concrete Test Specimen (ASTM C192).

b) Slump in Consistency of Mixture (ASTM C143). 
c) Compressive Strength of Cylindrical Specimens (ASTM C39)

d) Modulus of Elasticity (NSCP Section 5.8.5)

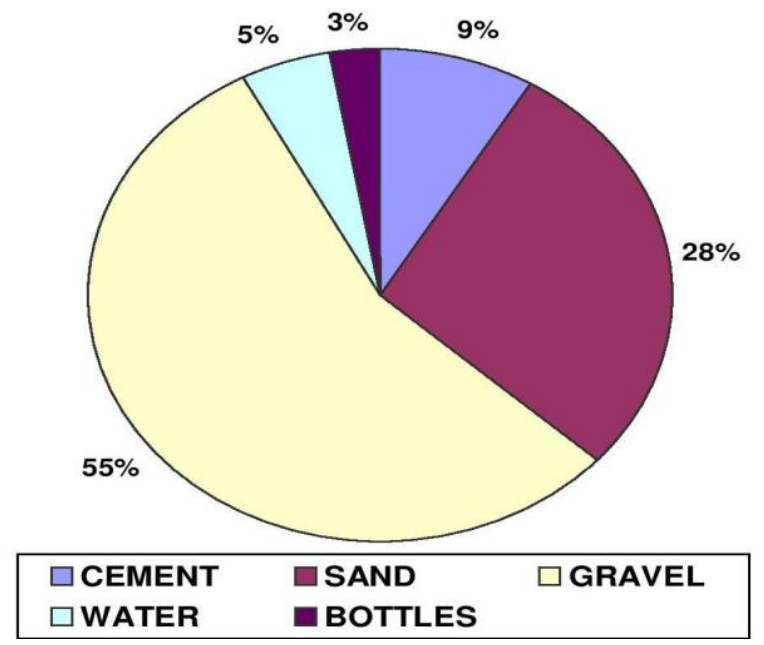

Figure 4. Design of Concrete Mixture with Recycled Glass Bottles

\section{Conclusion}

After determining the value of the results of the forgoing findings, the following conclusion were drawn: a) The use of recycled glass bottles as an alternative fine aggregate for concrete mix decreases the water-cement ratio depending on the amount present in the mixture; b) The use of recycled bottles as fine aggregate decreases the unit weight of concrete; c) The use of recycled bottles as an alternative for fine aggregate is not recommended for structural members such as columns, beams and suspended slabs; d) The modulus of elasticity is dependent with the compressive strength, and unit weight of concrete, hence, the recycled glass bottles as fine aggregate decreases the value for modulus of elasticity; e) The use of recycled bottles as an alternative fine aggregate decreases the amount of material cost for concrete due to recycled bottle aggregate; f) There is a positive projection in the availability of glass bottles due for its demands and flexibility in use.

\section{Appendix}
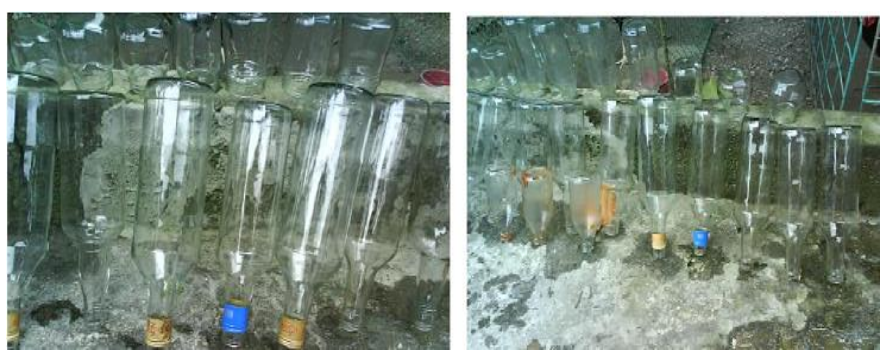

Figure 5. Drying of Cleaned Bottles 


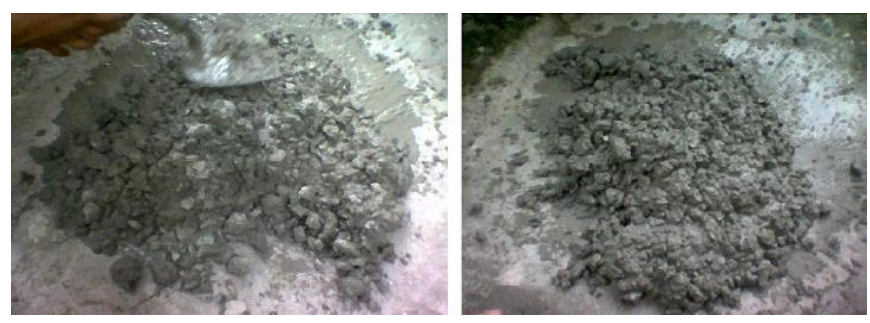

Figure 6. Drying of Cleaned Bottles

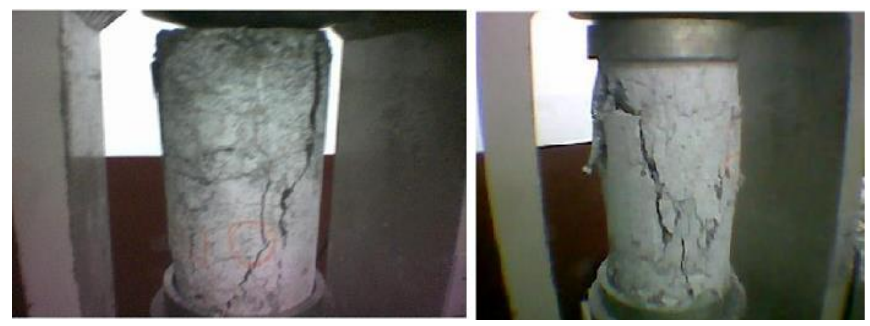

\section{Figure 7. Testing of Specimen Using Universal Testing Machine}

\section{References}

[1] L. Barbieri, A. Corradi and I. Lancellotti, "Glass Matrix Composites from Solid Waste Materials", Journal of the European Ceramic Society, vol. 21.4, (2001), pp. 453-460.

[2] T. U. Ganiron Jr, "Scrap Waste Tire as an Additive in Asphalt Pavement for Road Construction", International Journal of Advances in Applied Sciences, vol. 1.2, (2012), pp. 31-37.

[3] A. Luz and S. Ribeiro, "Use of Glass Waste as a Raw Material in Porcelain Stoneware Tile Mixtures", Ceramics International, vol. 33.5, (2007), pp. 761-762.

[4] T. U. Ganiron Jr, "Concrete Debris a Fine Aggregate for Architectural Finishing Mortar", Architectural Journal, vol. 2, no. 5, (2012).

[5] J. Srawley, "Wide Range Stress Intensity Factor Expressions for ASTM E 399 Standard Fracture Toughness Specimens", International Journal of Fracture, vol. 12.3, (1976), pp. 475-476.0

[6] T. U. Ganiron Jr, "Effects of Rice Hush as Substitute for Fine Aggregate in Concrete Mixture", International Journal of Advanced Science and Technology, vol. 58, (2013).

[7] M. Lines and A. Glass, "Principles and Applications of Ferroelectrics and Related Materials, Oxford University Press, (2001).

[8] T. U. Ganiron Jr, "Technical Specification of Concrete Hollow Blocks with Coconut Shells and Fiber as Aggregate", Proceedings of the 1st International Concrete Sustainability, Tokyo, Japan, (2013) May 27.

[9] H. Donza and E. F. Irassar, "High-Strength Concrete with different Fine Aggregate", Cement and Concrete Research, vol. 32, no. 11, (2002), pp. 1755-1761.

[10] M. Tavakoli and P. Soroushian, "Strengths of Recycled Aggregate Concrete Made using Field-Demolished Concrete as Aggregate", ACI Materials Journal, vol. 93, no. 2, (1996).

[11] T. U. Ganiron Jr, "Recycled Window Glass for Non-Load Bearing Walls", International Journal of Innovation, Management and Technology, vol. 3, no. 6, pp. 725-730, (2012) December.

[12] P. Pennarun, P. Dole and A. Feigenbaum, "Functional Barriers in PET Recycled Bottles Part I, Determination of Diffusion Coefficients in Bioriented PET with and without Contact with Food Simulants", Journal of Applied Polymer Science, vol. 92, no. 5, (2004), pp. 2845-2858

[13] T. U. Ganiron Jr, "Investigation on the use of Coco Coir Polypropylene as Thermal Insulator", International Journal of Advanced Science and Technology, vol. 59, (2013), pp. 13-26.

[14] T. U. Ganiron Jr, "Utilization and End-Users Acceptability of Compressed Lahar Sediment Blocks as wall Panel for Low Cost Housing", WSEAS Transactions on Environment and Development, vol. 9, no. 3, (2013), pp. 206-219.

[15] T. U. Ganiron Jr, "Recycling of Waste Coconut Shells as Substitute for Aggregates in Mix Proportioning of Concrete Hollow Blocks", WSEAS Transactions on Environment and Development, vol. 9, no. 4, (2013), pp. 290-300. 
[16] A. Bilodeau and V. M. Malhotra, "Concrete Incorporating High Volumes of ASTM Class F Fly Ashes: Mechanical Properties and Resistance to De-icing Salt Scaling and to Chloride-Ion Penetration”, ACI Special Publication SP-132, (1992), pp. 319-349.

[17] T. U. Ganiron Jr and N. Ucol-Ganiron, "Recycled Glass Bottles: An Alternative Fine Aggregates for Concrete Mixture", Proceedings of the 4th International Conference of Euro Asia Civil Engineering Forum, Singapore, (2013) June 26-27.

\section{Author}

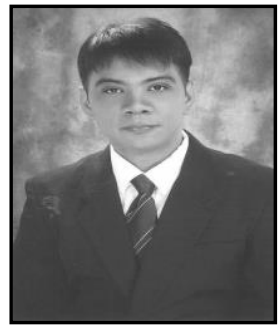

Tomas Ucol Ganiron Jr. This author obtained his Doctor of Philosophy in Construction Management at Adamson University (Philippines) in 2006, and subsequently earned his Master of Civil Engineering major in Highway and Transportation Engineering at Dela Salle University-Manila (Philippines) in 1997 and received Bachelor of Science in Civil Engineering major in Structural Engineering at University of the East (Philippines) in 1990. He is a registered Civil Engineer in the Philippines and Professional Engineer in New Zealand. His main areas of research interest are construction engineering, construction management, project management and recycled waste materials. He has been the resource person in various seminars in New Zealand (like in Auckland University of Technology, University of Auckland and University of Canterbury). He was connected with Advanced Pipeline System in New Zealand as Construction Manager wherein he supervised the sewerage and waterworks projects. He was the former Department Head of Civil Engineering in FEATI University (Manila) and former Department Head of Physics in Emilio Aguinaldo College (Manila). He is also very active in other professional groups like Railway Technical Society of Australasia and Australian Institute of Geoscientists where he became committee of Scientific Research. He has received the Outstanding Civil Engineer in the field of Education given by the Philippine Media Association Inc. (1996), ASTM Award CA Hogentogler (2008) by IPENZ in New Zealand and Outstanding Researcher (2013) in Qassim University, Buraidah City 
International Journal of Advanced Science and Technology Vol.61, (2013) 